\title{
Human errors identification in operation of meat grinder using TAFEI technique
}

\author{
Mohammadian M, MSc${ }^{1}$, Choobineh AR, $\mathrm{PhD}^{2}$, Mostafavi Nave AR, $\mathrm{MSc}^{3}$, Hashemi Nejad N, $\mathrm{PhD}^{4 *}$ \\ 1- MSc Student, Dept. of Occupational Health, School of Health, Kerman University of Medical Sciences, Kerman, Iran. \\ 2- Professor, Dept. of Occupational Health, School of Health, Shiraz University of Medical Sciences, Shiraz, Iran. \\ 3- MSc Student, Dept. of Occupational Health, School of Health, Shiraz University of Medical Sciences, Shiraz, Iran. \\ 4- Assistant Prof., Dept. of Occupational Health, School of Health, Kerman University of Medical Sciences, Kerman, \\ Iran.
}

\begin{abstract}
Received: May 2013, Accepted: December 2013

Background: Human error is the most important cause of occupational and non-occupational accidents. Because, it seems necessary to identify, predict and analyze human errors, and also offer appropriate control strategies to reduce errors which cause adverse consequences, the present study was carried out with the aim of identifying human errors while operating meat grinder and offer suggestions in order to reduce human errors in this human-machine system.

Materials and Methods: This is a descriptive study. In this ergonomic study the "Task Analysis for Error Identification (TAFEI)" technique was used in order to identify human errors while operating a meat grinder machine. According to this technique, firstly, tasks of human side of the interaction were described by Hierarchical Task Analysis (HTA) and then the State-Space Diagrams (SSDs) were drawn. Finally, after forming the TAFEI diagrams, the transition matrix table was prepared in order to identify human errors.

Results: After completing all the steps of TAFEI technique, the transition matrix table was formed. Results showed 49 illegal transition states; therefore, 49 human errors were identified and described while operating the meat grinder machine.

Conclusion: The results of this study showed how and under which conditions may meat grinder users do error in the human-machine interaction. In this regard, possible human errors resulting from non-ergonomic design of Iranian meat grinder machine were identified.
\end{abstract}

Keywords: Human, Identification, Product, Design, Methods

\section{Introduction}

We have all made mistakes while using different devices. Putting an empty kettle on the oven, forgetting to turn off the oven, burning clothes while ironing or a mistake in recording a video tape are all common errors we make in everyday life and which disturb us (1). People usually blame each other for these human errors. Such negative use of human error has made researchers to think more deeply about, why individuals commit errors in using professional and nonprofessional devices? Error is an inevitable part of human behavior. Such behaviors are hard to change; they cannot be forced into following error-free ways of doing things. Therefore, the best thing we can do is to improve working situations, develop better machines and design more suitable working methods. In this way we can provide them a more secure working environment (2).

Human error plays a key role in complicated industries like aviation, railway and nuclear power plant (3). It has been cited as a

\footnotetext{
* Corresponding author: Naser Hashemi Nejad, Dept. of Occupational Health, Kerman University of Medical Sciences, Kerman, Iran.

Email: n_hasheminejad@kmu.ac.ir
} 
primary cause in recent disasters among which are Bhopal disaster, Hillsborough football stadium disaster, Paddington train crash, Chernobyl disaster, Three Mile Island accident and Space Shuttle Challenger Disaster (4).

Reduction in human errors would naturally lead to reduction in costs $(4,5)$. Human error has been introduced as the most contributing factor to the accidents occurred in Iran during 1990 to 1999 (4). Based on the report issued by Iranian Social Security, 14000 accidents happen annually out of which 120 cases result in death and 150 cases lead to paralysis, although the actual numbers seem to be higher than this (6).

There are different factors which contribute to human errors; these factors may be personal, managerial or organizational. Some other examples include work method complexity, environmental condition, machine design, training methods, supervision methods and presence or absence of work instructions. Having analyzed about 75000 accidents, Heinrich concluded that unsafe acts (\%88), unsafe conditions (\%10) and unpredictable factors (\%2) account for these accidents (7). In another study done in Australia, \%83 of 2000 accidents were due to human error. A similar study done in Berlin Technical University showed that the cause of \%64 of all accidents was human failure (8, 9). It could be argued that human error is not a simple issue only caused by individual mistakes. It is rather the product design which leaves conditions for human error (1, 10). Accordingly, researchers are mostly concerned with the cost of these errors which is due to inappropriate design (1). Machine designers were looking for methods to be able to predict possible errors in using a certain machine (11). For this reason, they started product assessment of a pilot model by user. The pilot model reflects designer's ideas and hypotheses regarding humanmachine interaction and no points are made about other aspects of the product which may lead one to do error. To this end, some techniques and methods for predicting user's performance in relation to the machine were developed. Task Analysis for Error Identification (TAFEI) is one such technique which has advantages like time effectiveness, sequence of events and prediction of situations in which there may be errors. Through these techniques the product is analyzed before doing specific tasks (1). Currently there are more than 50 types of Human Error Identification (HEI) which are used diversely in power plants and petrochemical industry (12), air traffic control operations (13) and airlines (14).

Accidents associated with meat grinder use are one of the commonest accidents after the widespread use of technology. In the early years of its appearance in the market, the number of accidents resulting from meat grinder use was so high that Occupational Safety and Health Administration (OSHA) warned meat grinder manufacturers to follow standards on the control over hazardous energy (29 CFR 1910.147), general requirements for all machines (29 CFR 1910.212) and mechanical powertransmission apparatus (29 CFR 1910.219) (15). This led to a redesigning of meat grinder where designers lengthened its tube in order to reduce the possible accidents. In Ergonomics it is possible to decrease or even remove human errors through a good design achieved by the analysis of human-machine interaction. The present study was carried out with the aim of identifying possible human errors in operating an Iranian meat grinder.

\section{Material and Methods}

In this ergonomic study TAFEI technique was adopted to identify human errors. It 
comprises of three steps introduced below (16):

1. Doing Hierarchical Task Analysis (HTA) based on human behavior;

2. Drawing State Space Diagrams (SSDs) to show machine behavior; and

3. Forming transition matrix table which shows transition states and that leads to human error identification.

\section{Doing Hierarchical Task Analysis (HTA)}

HTA is the first step in TAFEI technique. The more accurate the HTA is done, the better result we can get from TAFEI technique. HTA refers to aims, operations and plans. Aims are machine task's nonobservable purposes. Operations comprise observable behaviors directed at achieving these aims. Finally, plans are non-observable decisions taken by the user. Here task is the super ordinate for all the states of task aims. This super ordinate is the highest level of the hierarchy which is then divided into multiple aims. Figure 1 presents HTA diagrams for the analyzed meat grinder. As it is shown in the figure, "operating meat grinder" is the super ordinate which includes 7 subordinate aims. Each of these 7 aims are operations intended to reach the higher level, i.e. "operating meat grinder" while continuing to be subdivided even further. Having completed this step, we turn to SSDs.

\section{Drawing State Space Diagrams (SSDs)}

SSD is the list of states which may happen in a machine. Each list has a common list under which is a list of output states (feedback). In a simple diagram the common state for meat grinder is "turn off" and "turn on". Figure 2 shows 8 SSD diagram from among 18 diagrams in the analyzed meat grinder. When drawing SSDs, care must be taken that outputs should exactly match common states of the machine. This is necessary in obtaining a correct task analysis and human error identification.

Having drawn SSDs, numbered plans obtained by HTA, should be inserted into it which shows what kind of human behavior changes the state of the machine. Later, these plans are drawn in transition state. This is the process through which a TAFEI diagram is prepared. Figure 3 shows some TAFEI diagrams related to the analyzed meat grinder machine.

\section{Forming transition matrix}

Transition matrix is an important step in TAFEI technique. All the possible states are inserted into this matrix. Transitions states of SSDs are put into the cells of the table. Transition matrix for 18 identified states in the analyzed meat grinder is presented in figure 4. Three approaches have been adopted to complete the matrix:

1. If the given transition is impossible, a dash is put in the respective cell.

2. If a given transition is both possible and desirable (i.e. user is heading towards the aim-a correct act), it is a legal transition which is shown by $\mathrm{L}$ in the table.

3. If a given transition is possible but undesirable (deviation from the desired aima wrong act), it is an illegal transition which is shown by $\mathrm{I}$ in the table.

\section{Results}

Figure 1 presents HTA diagrams for the analyzed meat grinder. As it is shown in the figure, "operating meat grinder" is the super ordinate which includes 7 subordinate aims. Each of these 7 aims are operations intended to reach the higher level, i.e. "operating meat grinder" while continuing to be subdivided even further. Figure 2 shows 8 SSD diagram from among 18 diagrams in the analyzed meat grinder. 
Table 1: Ten identified errors in the analyzed meat grinder using TAFEI technique

\begin{tabular}{|c|c|c|c|}
\hline ID & Error matrix & Error description & $\begin{array}{l}\text { Suggested ways to error } \\
\text { control }\end{array}$ \\
\hline 1 & $9 \times 13$ & $\begin{array}{l}\text { Error in connecting machine to the electricity while it is on } \\
\text { (possibility of damage to users) }\end{array}$ & Inclusion in the manual \\
\hline 2 & $13 \times 14$ & Error in turn on/off (possibility of damage to the machine) & $\begin{array}{l}\text { Design optimization, } \\
\text { Instruction labels }\end{array}$ \\
\hline 3 & $14 \times 15$ & $\begin{array}{l}\text { Error in switching to reverse mode while the machine is on } \\
\text { (possibility of damage to the machine) }\end{array}$ & $\begin{array}{l}\text { Design optimization, } \\
\text { Instruction labels }\end{array}$ \\
\hline 4 & $14 \times 17$ & $\begin{array}{l}\text { Error in switching to reverse mode when the stomper is in the } \\
\text { tube (possibility of damage to the machine) }\end{array}$ & $\begin{array}{l}\text { Design optimization } \\
\text { Warning labels }\end{array}$ \\
\hline 5 & $15 \times 17$ & $\begin{array}{l}\text { Error in pushing meat into grinder head (by hands, spoons,...) } \\
\text { when meat stomper is not available (possibility of damage to } \\
\text { the user and machine) }\end{array}$ & $\begin{array}{l}\text { Warning labels, } \\
\text { Service optimization, } \\
\text { Inclusion in the manual }\end{array}$ \\
\hline 6 & $15 \times 1,3 \times 13$ & $\begin{array}{l}\text { Error in adjusting electrical or mechanical functions when it is } \\
\text { switched on (possibility of damage to the user and machine) }\end{array}$ & $\begin{array}{l}\text { Design optimization, } \\
\text { Inclusion in the manual }\end{array}$ \\
\hline 7 & $4 \times 5$ & $\begin{array}{l}\text { Turning on when the machine is not correctly assembled } \\
\text { (possibility of damage to the machine) }\end{array}$ & $\begin{array}{l}\text { Design optimization, } \\
\text { Inclusion in the manual, } \\
\text { Instruction labels }\end{array}$ \\
\hline 8 & $12 \times 11$ & $\begin{array}{l}\text { Error in closing the cord box which may damage the cords } \\
\text { (possibility of damage to the machine) }\end{array}$ & Design optimization \\
\hline 9 & $9 \times 16,9 \times 15$ & $\begin{array}{l}\text { Turning the meat grinder on when the tube is stuffed with } \\
\text { meat (possibility of damage to the machine) }\end{array}$ & Inclusion in the manual \\
\hline 10 & $1 \times 13,1 \times 9$ & $\begin{array}{l}\text { Changing parts when the machine is switched on (possibility } \\
\text { of damage to users) }\end{array}$ & $\begin{array}{l}\text { Design optimization, } \\
\text { Inclusion in the manual }\end{array}$ \\
\hline
\end{tabular}




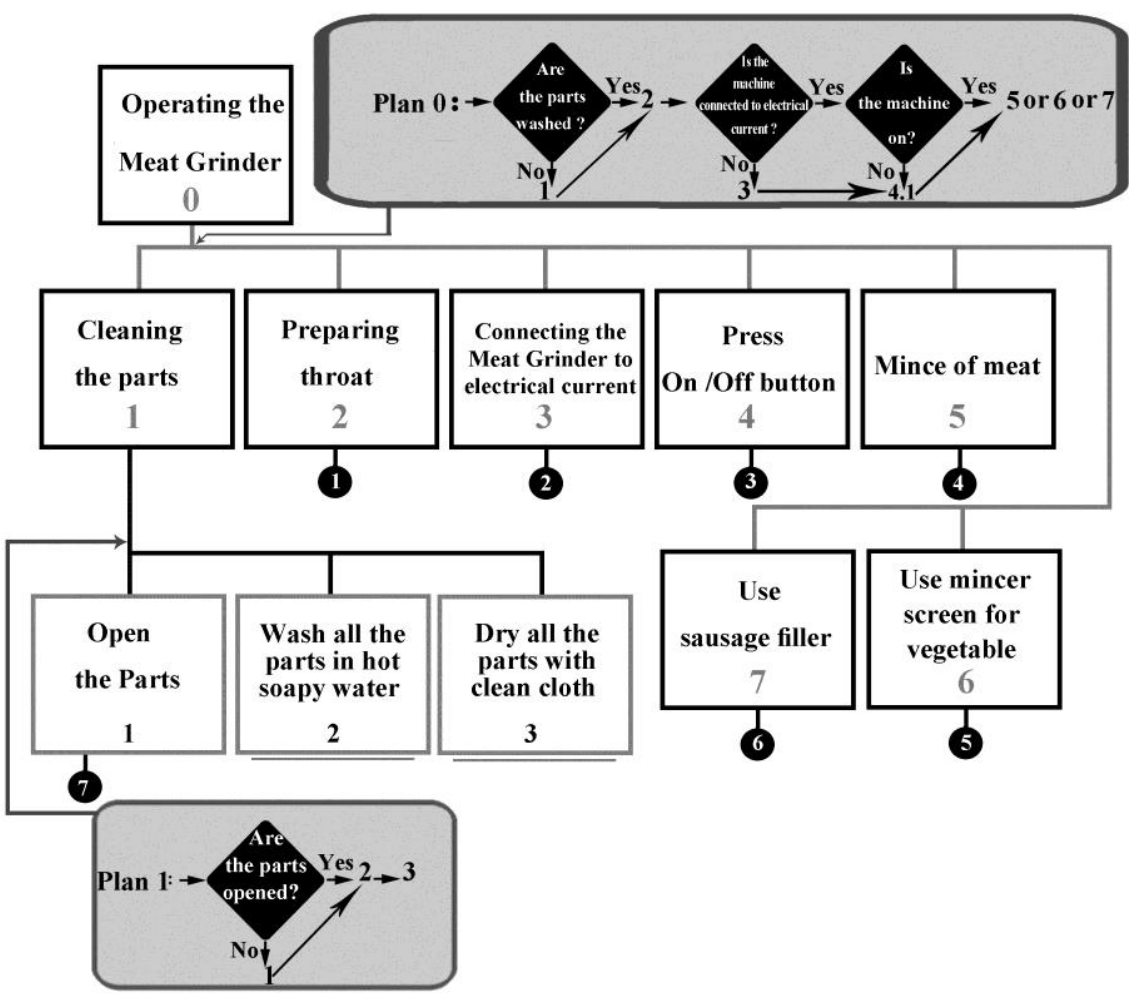

Figure 1: HTA diagram in the analyzed meat grinder

\begin{tabular}{|c|}
\hline $\mathbf{1}$ \\
\hline Open the parts \\
\hline $\begin{array}{c}\text { Trying to eject the plug } \\
\text { from the socket }\end{array}$ \\
\hline $\begin{array}{c}\text { Trying to disconnect the } \\
\text { tray from on the throat }\end{array}$ \\
\hline Trying to open the ring nut \\
\hline $\begin{array}{l}\text { Trying to disconnect the } \\
\text { parts exit inside the throat } \\
\text { includes mincer screen, cutter } \\
\text { scroll or sausage filler and } \\
\text { mincer screen for vegetable }\end{array}$ \\
\hline $\begin{array}{c}\text { Trying to disconnect the } \\
\text { throat from the mincer body }\end{array}$ \\
\hline Wait for cleaning the parts \\
\hline
\end{tabular}

\begin{tabular}{|c|}
\hline 2 \\
\hline $\begin{array}{c}\text { Cleaning the parts and } \\
\text { the mincer body }\end{array}$ \\
\hline Trying to washing the parts \\
\hline Trying to drying the parts \\
\hline
\end{tabular}

\begin{tabular}{|c|}
\hline Assemble \\
\hline $\begin{array}{c}\text { Trying to fit the scroll } \\
\text { inside the mincer body }\end{array}$ \\
\hline Trying to fit the cutter \\
\hline Trying to fit the mincer screen \\
\hline $\begin{array}{c}\text { Trying to fit the } \\
\text { sausage filler }\end{array}$ \\
\hline $\begin{array}{c}\text { Trying to fit the mincer } \\
\text { screen for vegetable }\end{array}$ \\
\hline $\begin{array}{c}\text { Trying to loosely fit } \\
\text { the ring nut }\end{array}$ \\
\hline Trying to adjust the locking screw \\
\hline $\begin{array}{c}\text { Trying to attach the } \\
\text { throat into the mincer body }\end{array}$ \\
\hline $\begin{array}{c}\text { Trying to tighten the } \\
\text { ring nut manually }\end{array}$ \\
\hline Trying to fit the tray \\
\hline $\begin{array}{c}\text { Wait for connect to } \\
\text { electrical current }\end{array}$ \\
\hline
\end{tabular}

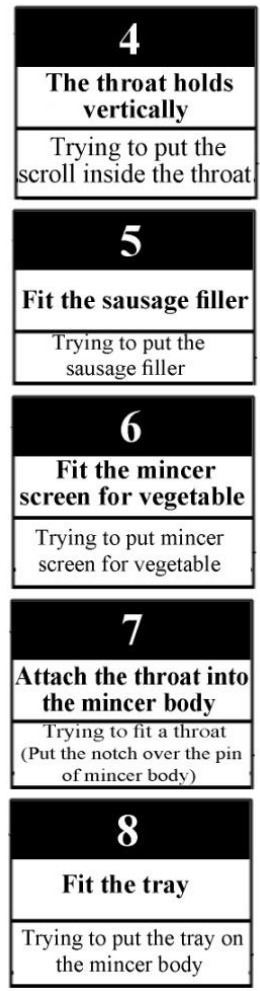

Figure 2: SSDs diagram in the analyzed meat grinder 


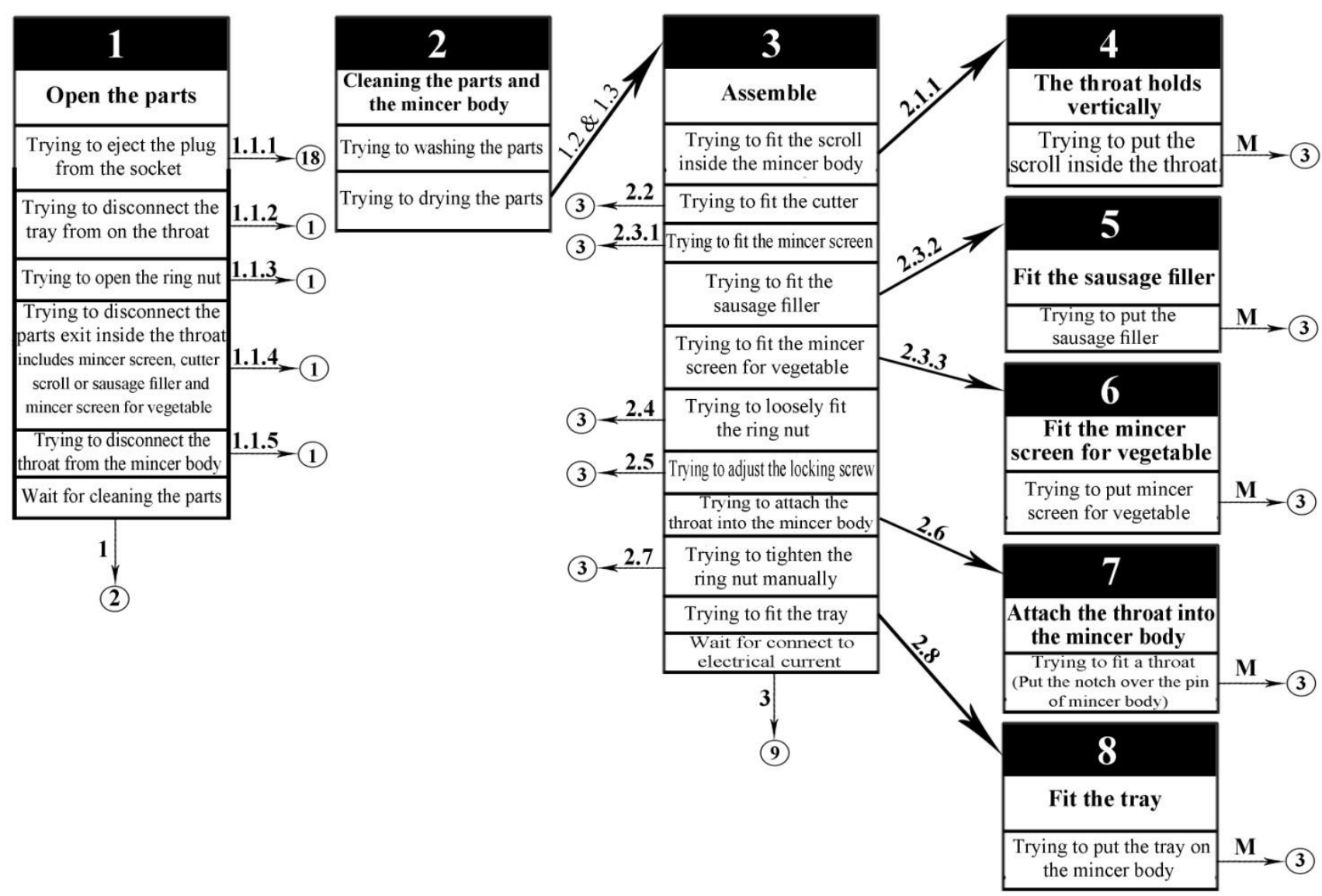

Figure 3: TAFEI diagram in the analyzed meat grinder

Figure 3 shows some TAFEI diagrams related to the analyzed meat grinder machine. Transition matrix for 18 identified states in the analyzed meat grinder is presented in figure 4.

Analysis of human errors in meat grinder use showed that there are 49 illegal transition states which means that there are 49 human errors in operating meat grinder. Table 1 presents 10 identified errors and illustrates ways to improve machine design. As it is shown in the table, errors 1 and 10 may injure users and errors 7, 4, 3, 2, 9 can damage the machine; errors 5 and 6 have the possibility to damage both machine and its user. Therefore, it is necessary for designers to obviate these errors. This can be done through many ways like optimizing the machine design, providing possible solutions in the manual and using warning labels. TAFEI technique flowchart is provided in figure 5 . 


\begin{tabular}{|c|c|c|c|c|c|c|c|c|c|c|c|c|c|c|c|c|c|c|}
\hline & 1 & 2 & 3 & 4 & 5 & 6 & 7 & 8 & 9 & 10 & 11 & 12 & 13 & 14 & 15 & 16 & 17 & 18 \\
\hline 1 & - & $\mathrm{L}$ & I & I & - & - & - & - & I & $\mathrm{L}$ & - & - & I & - & - & - & - & $\mathrm{L}$ \\
\hline 2 & $\mathrm{~L}$ & - & $\mathrm{L}$ & $\mathrm{L}$ & - & - & - & - & - & - & - & - & - & - & - & - & \multirow{2}{*}{\multicolumn{2}{|c|}{$\begin{array}{l}\text { L: Legal } \\
\text { I: Illegal }\end{array}$}} \\
\hline 3 & I & $\mathrm{L}$ & - & $\mathrm{L}$ & I & I & I & I & I & $\mathrm{L}$ & - & - & I & - & - & - & & \\
\hline 4 & - & $\mathrm{L}$ & $\mathrm{L}$ & - & I & I & I & I & - & - & - & - & - & - & - & - & - & - \\
\hline 5 & - & $\mathrm{L}$ & $\mathrm{L}$ & - & - & I & I & I & I & $\mathrm{L}$ & - & - & - & - & - & - & - & - \\
\hline 6 & - & $\mathrm{L}$ & $\mathrm{L}$ & I & - & - & I & I & I & $\mathrm{L}$ & - & - & - & - & - & - & - & - \\
\hline 7 & - & $\mathrm{L}$ & $\mathrm{L}$ & - & - & - & - & I & I & $\mathrm{L}$ & - & - & - & - & - & - & - & - \\
\hline 8 & - & $\mathrm{L}$ & $\mathrm{L}$ & I & I & I & $\mathrm{L}$ & - & $\mathrm{L}$ & $\mathrm{L}$ & - & - & - & - & - & - & - & - \\
\hline 9 & I & - & $\mathrm{L}$ & - & I & I & I & $\mathrm{L}$ & - & $\mathrm{L}$ & $\mathrm{L}$ & $\mathrm{L}$ & $\mathrm{L}$ & - & I & - & I & - \\
\hline 10 & $\mathrm{~L}$ & - & $\mathrm{L}$ & - & $\mathrm{L}$ & $\mathrm{L}$ & $\mathrm{L}$ & $\mathrm{L}$ & $\mathrm{L}$ & - & $\mathrm{L}$ & $\mathrm{L}$ & - & - & $\mathrm{L}$ & - & $\mathrm{L}$ & - \\
\hline 11 & - & - & - & - & - & - & - & - & $\mathrm{L}$ & $\mathrm{L}$ & - & I & - & - & - & - & - & $\mathrm{L}$ \\
\hline 12 & - & - & - & - & - & - & - & - & $\mathrm{L}$ & $\mathrm{L}$ & I & - & - & - & - & - & - & - \\
\hline 13 & I & - & I & - & - & - & - & - & $\mathrm{L}$ & $\mathrm{L}$ & - & - & - & I & $\mathrm{L}$ & - & $\mathrm{L}$ & - \\
\hline 14 & - & - & - & - & - & - & - & - & - & $\mathrm{L}$ & - & - & I & - & I & - & I & - \\
\hline 15 & I & - & - & - & - & - & - & - & I & $\mathrm{L}$ & - & - & $\mathrm{L}$ & I & - & $\mathrm{L}$ & I & $\mathrm{L}$ \\
\hline 16 & - & - & - & - & - & - & - & - & - & - & - & - & - & - & $\mathrm{L}$ & - & $\mathrm{L}$ & - \\
\hline 17 & - & - & - & - & - & - & - & - & I & $\mathrm{L}$ & - & - & $\mathrm{L}$ & I & I & $\mathrm{L}$ & - & - \\
\hline 18 & $\mathrm{~L}$ & - & $\mathrm{L}$ & - & - & - & - & - & - & - & - & - & - & - & $\mathrm{L}$ & - & - & - \\
\hline
\end{tabular}

Figure 4: Transition matrix in the analyzed meat grinder 


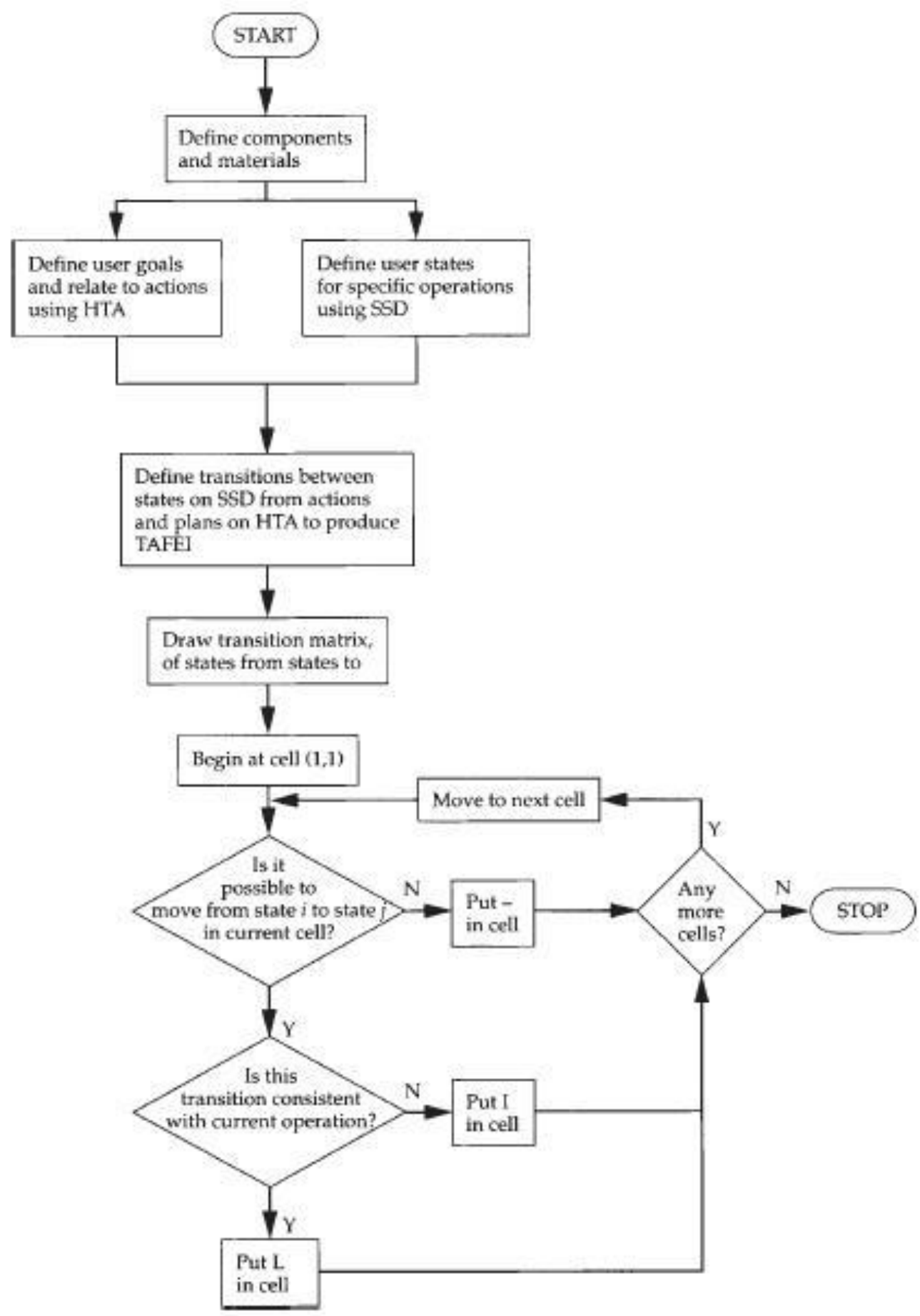

Figure 5: TAFEI technique flowchart

\section{Discussion}

Error prediction needs accessibility to a complete set of information about plausible events that are likely to lead one to do error. Almost all the techniques for human error prediction follow a common procedure: what acts may be done and how these acts cause 
human error. Such a procedure enables the analyst to pinpoint potential errors in humanmachine interaction (10). Stanton and Baber extending Human Error Template (HET) method, introduced 12 basic error modes. These error modes are: 1. Fail to execute; 2. Task execution Incomplete; 3 . Task executed in wrong direction; 4 . Wrong task executed; 5. Task repeated; 6. Task executed on the wrong interface element; 7. Task executed too early; 8 . Task executed too late; 9 . Task executed too much; 10. Task executed too little; 11. Misread information; and 12. Other modes (15).

In TAFEI technique, human interaction is described in terms of HTA. While different techniques can serve this purpose, HTA is the most appropriate one in that it is developed for particular tasks and that allows for a hierarchical analysis of tasks (17). TAFEI helps to identify possible but undesirable transition states that can be used in best designing of artificial products. Based on this technique, possible and desirable states facilitate machine operation.

The technique has been applied to products such as Automated Teller Machine systemsATMs (18), audio-cassette players (19), video-cassette recorders (20), kettles (21), medical informatics $(22,23)$ and industrial applications like electricity sub-stations (24), road-cleansing vehicles (25), together with numerous examples of public technology (26). Thimbleby et al. (27), too, made use of this technique in designing the ticket vending machine. In another study, Barber and Stanton analyzed human errors in Mitsubishi mt401 mobile telephone (22). They reported that TAFEI can predict $\% 68$ of these errors (17). In the same way, the results of the present study showed that most of human errors can be identified and controlled using this technique. Some of the identified errors are presented in table 1 . As it is clear from the examples, this technique can accurately identify errors. Iranian manufacturers rarely use error identification technique in designing stage (i.e. error prediction). Additionally, those errors identified through trial and error are mentioned in the manual while few users would read them. Experts believe that people are getting machine skills because products are usually used by users without recourse to the manual. Take a camera as an example; having unpacked the box, users would insert the battery and start taking photographs. Only when there is an unsuitable human-machine interaction would users check the manual (16).

Therefore, designers are recommended to reduce human errors by predicting them using such useful techniques as TAFEI. They should not just mention them in the manual. Unfortunately Iranian designers and manufacturers rarely profit from these techniques to facilitate machine operation. A main reason can be that universities and industries are going to opposite directions.

\section{Conclusion}

The results of this study showed how and when meat grinder users may commit errors in human-machine interaction. To this end, possible human errors in operating an Iranian meat grinder, which resulted from its nonergonomic design, were identified. Thus, if manufacturers and designers identify these errors in the designing stage using TAFEI technique, they will be able to improve human-machine interaction and facilitate its use.

\section{Acknowledgements}

The authors would like to thank all the people who cooperated with this research. 
Conflict of interests: Non declared.

\section{References}

1. Stanton NA, Baber C. Error by design: methods for predicting device usability. Design Studies 2002; 23(4):363-84.

2. American Institute of Chemical Engineers. AICHE (1994). Guidelines for Preventing Human Error in Process Safety. $1^{\text {nd }}$ ed. United States: New York. P80-97.

3. Basnyat S, Palanque P. A task pattern approach to incorporate user deviation in task models. Presented at the first ADVISES Young Researchers Workshop, Ris $\phi$ National Laboratory, Roskilde. 2005. P10-19.

4. Rahimikamal SH, Naslsaraji J, Mohammadfam I. Assessment of human error probability index for gas compressor station musters (region 3 of gas transmission operation). Journal of School of Public Health and Institute of Public Health Research 2009; 7(4):51-68.

5. Dekker S (2002). The field guide to human error investigation. Bedford. UK: Cranfied University Press. P67:02.

6. Ghalenoei M, Asilian H, Mortazavi SB, Varmazyar S. Human erroranalysis among petrochemical plant control room operators with human errorassessment and reduction technique. Iran Occupational Health 2009; 6(2):38-50.

7. Brauer RL (2006). Safety and health for engineers. $2^{\text {nd }}$ ed. New Jersey: Inc. Hoboken. P21-34.

8. Kariuki SG, Lowe K. Integrating human factors into process hazard analysis. Reliability Engineering \& System Safety 2007; 92(12):1764-73.

9. Konstandinidou M, Nivolianitou Z, Kiranoudis C, Markatos N. A fuzzy modeling application of CREAM methodology for human reliability analysis. Reliability Engineering \& System Safety 2006; 91(6):706-16.

10. Reason J (1990). Human error cambridge. $1^{\text {nd }}$ ed. United Kingdom, Cambridge University Press. P700-68.

11. Stanton N, Baber C. A systems approach to human error identification. Saf sci 1996; 22(13):215-28.
12. Kirwan B. The validation of three human reliability quantification techniques-THERP, HEART and JHEDI: Part 1 -technique descriptions and validation issues. Appl Ergon 1996; 27(6):359-73.

13. Shorrock ST, Kirwan B. Development and application of a human error identification tool for air traffic control. Appl Ergon 2002; 33(4):319-36.

14. Harris D, Stanton NA, Marshall A, Young MS, Demagalski J, Salmon P. Using SHERPA to predict design-induced error on the flight deck. Aerospace science and technology 2005; 9(6):525-32.

15. Stanton NA, Salmon P, Harris D, Marshall A, Demagalski J, Young MS, et al. Predicting pilot error: testing a new methodology and a multi-methods and analysts approach. Appl Ergon 2009; 40(3):464-71.

16. Stanton NA, Young MS (2003). A guide to methodology in ergonomics: designing for human use. London: Taylor \& Francis. P7280.

17. Baber C, Stanton NA. Task analysis for error identification: theory, method and validation. Theor. issues in ergon. sci. 2002; 3(2):212-27.

18. Burford BC, Baber C (1994). A user-centred evaluation of a simulated adaptive autoteller. $1^{\text {nd }}$ ed. Robertson Contemporary ergonomics, London: Taylor \& Francis. P46-56.

19. Baber C, Stanton NA. Task analysis for error identification: A methodology for designing error-tolerant consumer products. Ergonomics 1994; 37(11):1923-41.

20. Baber C, Stanton NA (1992). Defining problem in VCR use: the application of task analysis for error identification. $1^{\text {nd }}$ ed. London: Contemporary ergonomics, Taylor \& Francis. P418-23.

21. Baber C, Stanton NA. Rewritable routines in human interaction with public technology. Int J Cogn Ergon 1997; 1(4):237-49.

22. Baber C, Stanton N. Analytical prototyping of personal technologies: using predictions of time and error to evaluate user interfaces. In Proceeding of Interact conference, In M. Hirose editor. Interact'01, Amsterdam: IOS Press, 2001. P585-92.

23. Yamaoka T, Baber C. Three-point task analysis and human error estimation. In Proceedings of the Human Interface Symposium, Tokyo, 2000. P395-8.

24. Glendon AI, Clarke SG, McKenna E (2006). Human Safety and Risk Management. $2^{\text {nd }}$ ed. 
London: New York: Chapman \& Hall. P14453.

25. Stanton NA, Baber C. Task analysis for error identification. joint MRC/RNPRC/APRC Workshop on Task Analysis. Presented at the joint MRC/RNPRC/APRC Workshop on Task Analysis, Scarman House, University of Warwick. April 5-6, 1993.

26. Baber C, Stanton NA. Human error identification techniques applied to public technology: predictions compared with observed use. Appl Ergon 1996; 27(2):119-31.

27. Thimbleby H, Blandford A, Cairns P, Curzon $\mathrm{P}$, Jones $\mathrm{M}$. User interface design as systems design. In: Faulkner, $\mathrm{X}$ and Finlay, $\mathrm{J}$ and Detienne, F, editors. People and Computers XVI-Memorable Yet Invisible, Proceedings. Presented at the 16th British-HumanComputer-Interact-Group Annual Conference/European-Usability-ProfessionalsAssociation, London, England, September 2-6, 2002. P281-301. 